Artigos

Volume 11 - $2021 \mid$ n. 4

\title{
Políticas de Financiamento da Educação no Brasil: impasses para a valorização docente
}

Daniel Stockmann

Universidade Federal de Mato Grosso do Sul (UFMS), Campo Grande/MS - Brasil

\section{Resumo}

Este artigo consiste em uma análise documental sobre as políticas de financiamento da educação básica brasileira ao longo do século passado e início deste. Preliminarmente o texto parte de uma abordagem qualitativa, com a releitura da bibliografia disponível sobre os percentuais de financiamento ao longo da história. Partindo da situação demográfica da sociedade, pretende-se compreender as opções econômicas e políticas do Estado brasileiro e de que maneira o protagonismo do capital orientou as políticas públicas de valorização do trabalho docente. Ao fim, foca-se no perfil dos professores, descrevendo a divisão sexual de seu trabalho e os avanços obtidos com a implementação da política de fundos, medida fundamental para a manutenção e desenvolvimento do ensino.

Palavras-chave: Financiamento Educacional. Trabalho Docente. Políticas Públicas.

\section{Education Financing Policies in Brazil: impasses for teacher}

\section{appreciation}

\begin{abstract}
This article consists of a document analysis of financing policies for basic Brazilian education throughout the last century and the beginning of this century. Preliminarily the text starts from a qualitative approach, with a re-reading of the available bibliography on the percentages of funding throughout history. Based on the demographic situation of society, it is intended to understand the economic and political options of the Brazilian State and how the role of capital has guided public policies for valuing teaching work. In the end, it focuses on the profile of teachers, describing the sexual division of their work and the progress made with the implementation of the fund policy - a fundamental measure for the maintenance and development of teaching.
\end{abstract}

Keywords: Education Financing. Teaching Work. Public Policy. 
Políticas de Financiamento da Educação no Brasil

\title{
Introdução
}

Quando se reflete sobre as políticas educacionais e suas consequências sobre o trabalho docente, um aspecto relevante a ser considerado é o aumento demográfico brasileiro. Em 1900, a população era de 17,4 milhões, em 1940 era de 41,2 milhões, em 1970 de 93 milhões, nos anos 2000 havia saltado para 165,7 milhões de pessoas e, em 2011, para 190,7 milhões. Esse aumento populacional é consequência de um conjunto de fatores, como o aumento da expectativa de vida em virtude de melhores condições sanitárias, avanço da ciência médica aliadas à falta de políticas de planejamento familiar, sem contar que na segunda metade do século XX não houve conflitos bélicos significativos e tampouco epidemias, se comparados com outros momentos históricos.

A expansão populacional que o Brasil experimentou ao longo do século passado, especialmente a partir da segunda metade do referido período, conjugada ao crescimento vegetativo da população, demandou novos e maiores espaços de mercado de trabalho e o crescente processo de preparação para tal, especialmente com a escolarização1.

O êxodo rural protagonizado na segunda metade do século $X X$, fruto do processo de industrialização tardio pelo qual o País passou, exigiu, dentre outras políticas públicas, como habitação e saneamento básico, a intensificação da necessidade de expansão e aprimoramento das escolas urbanas.

O aumento da obrigatoriedade do ensino de 4 para 8 anos, consolidado na Lei de Diretrizes e Bases $n^{\circ} 5.692$ de 1971, por exemplo, exigiu praticamente o dobro de demandas humanas, sem que houvesse necessariamente a mesma proporção de investimentos orçamentários em ensino ${ }^{2}$. Isso simboliza um passo na direção da desprofissionalização, ou seja, da precarização docente, se é que se pode afirmar que havia profissionalização no sentido estrito. Outro aspecto-chave seria certa incapacidade administrativa para lidar com o aumento de demandas de ensino, tanto no aspecto remuneratório quanto nas relações contratuais e trabalhistas.

\begin{abstract}
O caos administrativo que o aumento acelerado da quantidade de docentes representou teve alguns efeitos, no que concerne à profissionalização: passou-se de uma situação em que as condições institucionais da escola permitiam que se delimitasse um espaço de competência profissional para um momento que pode ser considerado como de desprofissionalização, uma vez que as condições de trabalho se degradaram visivelmente e a contratação emergencial de docentes implicou a relativização dos requisitos de formação inicial. Some-se a isso a deterioração dos níveis salariais e temos uma situação na qual boa parte desses 'docentes de emergência' não construía vínculos com as escolas nas quais eram chamados para trabalhar, havendo uma rotatividade docente acentuada, com óbvios prejuízos pedagógicos (VICENTINI; LUGLI, 2009, p. 90).
\end{abstract}

O Quadro 1 abaixo reproduz a evolução dos percentuais de recursos destinados à educação. Observa-se que, em momentos de regimes democráticos, houve expansão de

1 O crescimento demográfico foi significativo no último século em virtude de melhores condições de saúde, fluxos migratórios, dentre outros motivos, conforme https://mundoeducacao.bol.uol.com.br/geografia/crescimentopopulacao-brasileira.htm. Acesso em: 07 abr. 2020.

2 Os percentuais orçamentários mínimos de 18\% e 25\% para União, estados e municípios, respectivamente, presentes na Constituição Federal de 1988, são, ainda que insuficientes, ligeiramente superiores aos previstos em constituições anteriores. 
recursos, enquanto que, em momentos ditatoriais, retração ou mesmo ausência total de investimentos (MATO GROSSO DO SUL, 2014).

Quadro 1 - Percentual de recursos vinculados à educação no Brasil

\begin{tabular}{|c|c|c|c|c|}
\hline Anos & Constituições/Leis & União & Estados e DF & Municípios \\
\hline 1934 & $\begin{array}{l}\text { Constituição Federal de } \\
1934\end{array}$ & $10 \%$ & $20 \%$ & $10 \%$ \\
\hline 1937 & $\begin{array}{l}\text { Constituição Federal de } \\
1937\end{array}$ & - & & \\
\hline 1942 & Decreto-Lei n 4.958 & & 15 a $20 \%$ & 10 a $15 \%$ \\
\hline 1946 & $\begin{array}{l}\text { Constituição Federal de } \\
1946\end{array}$ & $10 \%$ & $20 \%$ & $20 \%$ \\
\hline 1961 & Lei Federal $n^{\circ} 4.024$ & $12 \%$ & $20 \%$ & $20 \%$ \\
\hline 1967 & $\begin{array}{l}\text { Constituição Federal de } \\
1967\end{array}$ & & & \\
\hline 1969 & Emenda Constitucional I & 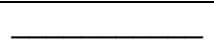 & & $20 \%$ \\
\hline 1971 & Lei Federal n 5.692 & - & & $20 \%$ \\
\hline 1983 & $\begin{array}{l}\text { Emenda Constitucional } \\
n^{\circ} 24\end{array}$ & $13 \%$ & $25 \%$ & $25 \%$ \\
\hline 1988 & $\begin{array}{l}\text { Constituição Federal de } \\
1988\end{array}$ & $18 \%$ & $25 \%$ & $25 \%$ \\
\hline
\end{tabular}

Fonte: Plano Estadual de Educação de Mato Grosso do Sul/2014-2024.

Conforme os dados acima, ainda que houvesse certo investimento público, o número de atendimento com a mesma proporção do orçamento tornou-se notoriamente insuficiente para manter os patamares anteriores.

Com menos dinheiro o impacto, tanto em recursos materiais quanto humanos, foi inevitável. Os professores, ainda que tenham aumentado numericamente, passaram a ganhar menos, aproximando-se das condições laborais do operariado.

A aproximação do professor com o operário traz à luz uma imensa discussão sobre o conceito de proletário. Seria o professor o novo proletário? A crise do petróleo, que atingiu boa parte do mundo nos anos de 1970, a crise do Estado de Bem-Estar Social e o regime ditatorial que o País vivenciava culminou com o surgimento de fortes movimentos sociais por democratização e justiça social.

É certo que a ascensão dos governos de Margaret Thatcher, na Inglaterra, e Ronald Reagan, nos Estados Unidos, reascendeu os ideais liberais como alternativa supostamente necessária para substituir o Walfare State, que, na concepção destes, não estaria mais respondendo eficazmente aos problemas econômicos e sociais. O papel do Estado deveria ser reduzido ao mínimo possível, quase que exclusivamente a um mero fiscal e garantidor do sistema produtivo e da reprodução do próprio sistema capitalista. Em linhas gerais, isso marca o surgimento do neoliberalismo, que, via entidades internacionais, como o Banco Mundial e o Fundo Monetário Internacional, propagou-se nos países latino-americanos, incluindo o Brasil.

Nos anos de 1990, a agenda neoliberal protagonizou o cenário político e econômico nacional. Embora a Constituição Federal de 1988 tenha sido considerada avançada e garantista, do ponto de vista social, a eleição de Fernando Collor de Melo simbolizou a abertura para a década pró-mercado. Os governos de Fernando Henrique Cardoso deram 
Políticas de Financiamento da Educação no Brasil

prosseguimento a esse processo ao implementar a Reforma do Estado, intensificando a agenda privatista, privilegiando o capital monopolista através do rentismo bancário e abertura aos interesses externos. Isso gerou forte tensão na sociedade civil, uma vez que houve "[...] a radicalização da política de cortes nos gastos sociais e de desregulamentação do mercado de trabalho" (BOITO JR., 1999, p. 12). Somaram-se a isso a recente e imatura abertura democrática bem como a conquista do direito de sindicalização do setor público.

Dessa forma, a última década do século XX marcou certo paradoxo: por um lado o Estado precisava cumprir com as políticas sociais contidas na Constituição Federal de 1988, garantindo subsídios mínimos com a vinculação de recursos para algumas áreas sociais, como educação, por exemplo, e, por outro, conceder espaço à expansão do mercado, com o discurso do mérito e da eficiência. É nesse cenário que a correlação de forças entre a classe trabalhadora e os interesses do capital se explicita.

A Lei de Diretrizes e Bases da Educação Nacional só foi aprovada em 1996, ou seja, quase dez anos após o texto constitucional, por conta da variedade de concepções de modelos educacionais existentes e discutidos naquele momento. Novamente voltou à baila a concepção de educação como bem de consumo em detrimento de um projeto inclusivo e universal, como direito social.

Sobre o tenso processo de tramitação das propostas que culminaram na Lei $n^{\circ} 9.394$, de 20 de dezembro de 1996, Oliveira (1997, p. 2) afirma que:

Se a sociedade brasileira é dividida em classes com interesses não apenas diferentes, mas antagônicos, próprios da estrutura desta sociedade, o embate social que ocorre na base material se reflete no Congresso Nacional, local por excelência de articulação política e de incorporação das lutas sociais, para onde convergem os conflitos decorrentes dos interesses contraditórios da sociedade, para onde são remetidos documentos divergentes, por grupos ou segmentos de classe, que requerem soluções próprias sobre antagonismos que atravessam a sociedade em direção contrária.

Vê-se que a consecução das diretrizes da educação nacional esteve atrelada ao interesse hegemônico daquele momento, a política econômica dos governos desse período eram fatores determinantes, ainda que a mobilização, tanto corporativa da categoria docente quanto da sociedade como um todo, fosse intensa.

Mesmo a Constituição Federal de 1988 tendo consolidado os valores mínimos de 18\% para a União e $25 \%$ para estados e municípios, a serem destinados à educação, houve a necessidade de criar-se critérios mais específicos para se conseguir que esses valores mínimos fossem cumpridos.

Esses percentuais precisam ser destinados na Manutenção e Desenvolvimento de Ensino (MDE). A definição do que seria manutenção e desenvolvimento de ensino é importante, pois muitas ações que não possuem qualquer relação direta com a educação poderiam ser concebidas como "manutenção e desenvolvimento de ensino".

Tendo em vista essa pluralidade de políticas públicas que serviriam de pretexto para outros destinos aos recursos, podendo ocorrer o desvio de finalidade, dada a histórica tradição clientelista e patrimonialista que marcam a sociedade brasileira, a LDB de 1996 define a questão da seguinte forma: 
Políticas de Financiamento da Educação no Brasil

Art. 70. Considerar-se-ão como de manutenção e desenvolvimento do ensino as despesas realizadas com vistas à consecução dos objetivos básicos das instituições educacionais de todos os níveis, compreendendo as que se destinam a:

I - remuneração e aperfeiçoamento do pessoal docente e demais profissionais da educação;

II - aquisição, manutenção, construção e conservação de instalações e equipamentos necessários ao ensino;

III - uso e manutenção de bens e serviços vinculados ao ensino;

IV - levantamentos estatísticos, estudos e pesquisas visando precipuamente ao aprimoramento da qualidade e à expansão do ensino;

V - realização de atividades-meio necessárias ao funcionamento dos sistemas de ensino;

VI - concessão de bolsas de estudo a alunos de escolas públicas e privadas;

VII - amortização e custeio de operações de crédito destinadas a atender ao disposto nos incisos deste artigo;

VIII - aquisição de material didático-escolar e manutenção de programas de transporte escolar (BRASIL, 1996, p. 34).

Logo a seguir o texto legal vai além, ao especificar para quais finalidades os recursos não podem ser utilizados como manutenção e desenvolvimento de ensino:

Art. 71. Não constituirão despesas de manutenção e desenvolvimento do ensino aquelas realizadas com:

I - pesquisa, quando não vinculada às instituições de ensino, ou, quando efetivada fora dos sistemas de ensino, que não vise, precipuamente, ao aprimoramento de sua qualidade ou à sua expansão;

II - subvenção a instituições públicas ou privadas de caráter assistencial, desportivo ou cultural;

III - formação de quadros especiais para a administração pública, sejam militares ou civis, inclusive diplomáticos;

IV - programas suplementares de alimentação, assistência médico-odontológica, farmacêutica e psicológica, e outras formas de assistência social;

$\mathrm{V}$ - obras de infraestrutura, ainda que realizadas para beneficiar direta ou indiretamente a rede escolar;

$\mathrm{VI}$ - pessoal docente e demais trabalhadores da educação, quando em desvio de função ou em atividade alheia à manutenção e desenvolvimento do ensino (BRASIL, 1996, p. 34).

Há que se destacar também que a grande extensão territorial do país, assim como a pluralidade de redes de ensino, como a heterogênea concepção de planos de carreiras, eram fatores de assimetrias tanto na captação quanto na aplicação de recursos públicos. O orçamento público precisava ser mais bem investido, reduzindo as assimetrias na qualidade da manutenção do ensino.

É nesse ínterim que surgem as políticas de fundos. São pensadas como um conjunto de regras contábeis de arrecadação de recursos para que se constituam fundos para a manutenção e desenvolvimento do ensino. A primeira culminou na Emenda Constitucional $n^{\circ}$ 14 de 1996, regulamentada pela Lei no 9.424, de 24 de dezembro de 1996, instituindo o Fundo de Manutenção e Desenvolvimento do Ensino Fundamental e de Valorização do Magistério (FUNDEF). Na prática, o FUNDEF tinha o caráter já elencado anteriormente, de servir como política pública redistributiva.

Apesar de ser uma proposta interessante, o FUNDEF possuía algumas lacunas, uma vez que não abrangia toda a educação básica e deixava de fora modalidades de ensino, como 
Políticas de Financiamento da Educação no Brasil

o Ensino de Jovens e Adultos, por exemplo. Tratava-se de um fundo contábil voltado apenas para o ensino fundamental. Após transcorridos 10 anos, validade projetada inicialmente para lei, com ampla discussão no meio acadêmico e sindical, foi consolidada a Emenda Constitucional $n^{\circ} 53$, de 19 de dezembro de 2006, que posteriormente foi regulamentada pela Lei $n^{\circ} 11.494$, de 20 de junho de 2007, instituindo o Fundo de Manutenção e Desenvolvimento da Educação Básica e de Valorização dos Profissionais da Educação (FUNDEB).

Interessante ressaltar que ambas as leis tinham como ideia norteadora uma nova sustentação, equalização e racionalidade no uso dos recursos em educação, tanto no aspecto estrutural, material ou físico quanto humano do ensino. Do montante de recursos havia um percentual majoritário $(60 \%)$ a ser revertido em salários dos servidores. Nesse sentido, haveria que se debater um valor mínimo a ser pago nacionalmente aos docentes. Após estudos sobre todo o processo histórico de militância social pró-valorização salarial, chegouse ao consenso possível e a aprovação da Lei no 11.738, em 16 de julho de 2008, estipulando o Piso Salarial Profissional Nacional (PSPN), o qual, além de estabelecer o valor mínimo, normatizou a quantidade mínima de tempo destinada à preparação de aulas em $1 / 3$ do total da jornada.

No entanto, a aprovação da Lei do PSPN não ocorreu sem embates, antes, durante e principalmente depois. Governos dos estados de Paraná, Santa Catarina, Rio Grande do Sul, Ceará e Mato Grosso do Sul ingressaram no Supremo Tribunal Federal (STF) com a ADIN no 4167, alegando que a União invadia a autonomia dos estados, ferindo o pacto federativo. Em dezembro de 2008, o STF recebeu o pedido, sendo que seu mérito foi julgado favorável aos professores em abril de 2011.

Havia uma preocupação por parte dos referidos gestores de que os recursos destinados à educação seriam onerosos para o orçamento e poderia implicar em improbidade administrativa conforme a Lei de Responsabilidade Fiscal (LRF), uma vez que a categoria docente é uma das mais numerosas tanto nos estados quanto nos municípios.

\section{Perfil e vinculação trabalhista dos professores brasileiros}

Tendo como base o Censo Escolar, em 2007 o Brasil tinha 1.882.961 professores atuando na educação básica ${ }^{3}$. A participação masculina era tímida em praticamente todas as etapas do ensino, aumentando consideravelmente à medida que se avançava nos níveis de ensino, chegando a $35 \%$ no ensino médio e superando a participação feminina apenas na modalidade educação profissional, onde pessoas do sexo masculino chegavam a $53,3 \%$. No cômputo geral, a profissão docente era 81,6\% feminina (BRASIL, 2009).

O componente "raça" ou "cor" era bem diversificado, constituindo um retrato aproximado de cada região do País. Sobre a faixa etária predominante, destaca-se que $55 \%$ dos professores possuíam entre 30 e 45 anos de idade. O número de professores que atuavam em apenas uma escola era de $80,9 \%$ do total, enquanto que docentes atuantes em duas escolas equivaliam a $16 \%$ do total, e o número que atendia três ou mais escolas representava $3,1 \%$ (BRASIL, 2009).

3 Esses dados encontram-se em: http://portal.mec.gov.br/dmdocuments/estudoprofessor.pdf. Acesso em: 12 fev. 2019. 
Políticas de Financiamento da Educação no Brasil

Segundo esse levantamento, 1.507.096 professores atuavam exclusivamente na rede pública contra 309.644 que trabalhavam com exclusividade na rede privada, ou seja, apenas $16,4 \%$. Sobre o perfil de formação, 1.288 .688 docentes possuíam nível superior completo (90\%), perfazendo $68,4 \%$ de todos os docentes (BRASIL, 2009).

Em levantamento realizado pelo Instituto Nacional de Estudos e Pesquisas Educacionais Anísio Teixeira (INEP), em 20184, com dados dos Censos Escolares de 2009, 2013 e 2017, respectivamente, sobre a atuação dos professores nas diferentes etapas da educação básica, chega-se à seguinte conclusão:

\section{Quadro 2 - Número de Professores da Educação Básica por etapas de ensino no Brasil - 2009/2013/2017}

\begin{tabular}{|c|c|c|c|}
\hline ANOS & 2009 & 2013 & 2017 \\
\hline TOTAL & 1.857 .278 & 2.017 .071 & 2.078 .910 \\
\hline Educação Infantil & 377.560 & 478.811 & 557.541 \\
\hline Anos Iniciais & 737.833 & 750.366 & 761.737 \\
\hline Anos Finais & 785.209 & 802.902 & 764.731 \\
\hline Ensino Médio & 460.023 & 507.617 & 509.794 \\
\hline
\end{tabular}

Fonte: Elaborada pelo autor com dados do INEP (2017).

Lembrando que a soma do número de professores do quadro acima não reflete o número total de docentes, porque muitos atuam em vários níveis de ensino, sendo, portanto, contabilizados mais de uma vez.

Em linhas gerais:

[...] O estudo demonstrou que os professores típicos brasileiros em 2017 são mulheres $(81 \%)$, de raça/cor branca $(42 \%)$ ou parda $(25,2 \%)$, com idade média de 41 anos, alocadas, prioritariamente, nas etapas iniciais da educação básica. Uma minoria declarou ser portadora de necessidades especiais $(0,31 \%$ em 2017$)$. A escolaridade do professor é predominantemente de nível superior em todas as etapas de ensino - sendo que a maior parte é em licenciatura. Dos graduados, $36 \%$ são portadores de títulos de pós-graduação lato ou stricto sensu. A maior parte dos professores é concursada e leciona em apenas uma escola, 38\% em uma única turma e $40 \%$ ministra uma única disciplina (BRASIL, 2018, p. 05).

Veja-se que o espectro geral não mudou muito e que a docência continua sendo uma profissão majoritariamente feminina no Brasil. Isso se explica pelo processo histórico constituinte do ideário da educação como arte do "cuidar", em que a mulher, em sociedades patriarcais, teve papel preponderante, conforme já discutido anteriormente neste trabalho.

\footnotetext{
4 Conforme publicado em: http://portal.inep.gov.br/informacao-da-publicacao/lasset_publisher/6JYIsGMAMkW1/document/id/1473981. Acesso em: 14 fev. 2019.
} 
Quadro 3 - Investimento dos recursos destinados à educação no Brasil

\begin{tabular}{|c|c|c|c|c|c|c|}
\hline Recurso & DEPEN & ICIA ADI & TRATIV & & & \\
\hline & Total & Pública & Federal & Estadual & Municipal & Privada \\
\hline $\begin{array}{ll}\text { Biblioteca/Sala } & \text { de } \\
\text { leitura } & \end{array}$ & $87,5 \%$ & $85,7 \%$ & $98,1 \%$ & $85,4 \%$ & $82,7 \%$ & $91,9 \%$ \\
\hline Banheiro (dentro/fora) & $97,1 \%$ & $96,4 \%$ & $99,8 \%$ & $96,3 \%$ & $99,5 \%$ & $98,8 \%$ \\
\hline Banheiro PNE & $62,5 \%$ & $60 \%$ & $93,8 \%$ & $59,1 \%$ & $57,6 \%$ & $68,7 \%$ \\
\hline Dependências PNE & $46,8 \%$ & $44,3 \%$ & $79,5 \%$ & $43,4 \%$ & $37,7 \%$ & $52,7 \%$ \\
\hline $\begin{array}{ll}\text { Laboratórios } & \text { de } \\
\text { ciências } & \end{array}$ & $44,1 \%$ & $38,8 \%$ & $83,4 \%$ & $37,5 \%$ & $28,8 \%$ & $57,2 \%$ \\
\hline $\begin{array}{ll}\text { Laboratório } & \text { de } \\
\text { informática } & \end{array}$ & $78,1 \%$ & $82,1 \%$ & $99,8 \%$ & $81,8 \%$ & $64,4 \%$ & $68,4 \%$ \\
\hline Internet & $95,1 \%$ & $93,6 \%$ & $99,3 \%$ & $93,5 \%$ & $85,9 \%$ & $98,7 \%$ \\
\hline Banda larga & $84,9 \%$ & $81,1 \%$ & $95,1 \%$ & $80,8 \%$ & $70,2 \%$ & $94,1 \%$ \\
\hline $\begin{array}{l}\text { Pátio (coberta e } \\
\text { descoberta) }\end{array}$ & $79,2 \%$ & $74,8 \%$ & $89,9 \%$ & $74,2 \%$ & $88 \%$ & $90,1 \%$ \\
\hline $\begin{array}{l}\text { Quadra de esportes } \\
\text { (coberta e descoberta) }\end{array}$ & $75,9 \%$ & $72,8 \%$ & $70 \%$ & $72,8 \%$ & $73,3 \%$ & $83,6 \%$ \\
\hline
\end{tabular}

Fonte: INEP/Censo Escolar (2018)

O quadro acima mostra dados relacionados aos recursos disponíveis. Observa-se que a rede federal concentra o maior aporte na maioria dos quesitos, equiparando ou mesmo superando a rede privada, seguida logo após pelas redes estaduais e, por fim, municipais. Entretanto, contrastando-se as redes públicas com as privadas, estas superam aquelas em termos de infraestrutura.

Percebe-se a variedade e relativa distância das redes municipais estaduais com relação às federais. Isso se dá pela evidente desproporção numérica se comparadas e também por efeitos históricos: a histórica descentralização administrativa da educação, fruto do pacto federativo, não garantiu aporte financeiro proporcional às redes de ensino. O que se observou foi uma descentralização no que compete à administração financeira, mas uma desconcentração no que concerne à fiscalização e avaliação. Ou seja, embora estados e municípios não estejam hierarquicamente submetidos à União quanto ao cumprimento e aplicação de suas receitas em educação, eles precisam cumprir normas mínimas de qualidade e equidade emanadas do governo federal.

A proporção de recursos para a educação depende diretamente do resultado do processo produtivo bem como da ideologia dominante, ou seja, do tipo de sociedade que se pretende formar.

A análise da remuneração docente no Brasil pode se traduzir em um esforço avaliativo complexo, pois o País é muito extenso, as redes de ensino diversificadas e, os estatutos socioprofissionais, heterogêneos. Conceber determinada remuneração como ideal pode configurar-se em algo relativo, dado que, o que um profissional recebe como satisfatório em um município, estado ou região, pode ser insuficiente para sobreviver em outra localidade, em virtude das variações relativas ao custo de vida.

5 Disponível em: http://portal.inep.gov.br/artigo/-/asset_publisher/B4AQV9zFY7Bv/content/id/6384770. Acesso em: 16 fev. 2019. 
Políticas de Financiamento da Educacão no Brasil

No entanto, é necessário que haja um parâmetro mínimo abaixo do qual seria insustentável afirmar que o trabalhador tenha condições mínimas de reprodução de sua força de trabalho. É nesse sentido que se faz relevante falar em piso salarial. Entretanto, faz-se pertinente compreender o atual estágio de desenvolvimento do capitalismo e as articulações de resistências por parte da sociedade, por meio da classe trabalhadora. É nesse sentido que discutir a história da categoria docente é imprescindível.

A Constituição Federal de 1988 , já em seu artigo $1^{\circ}$, ao falar sobre a dignidade da pessoa humana e dos valores sociais do trabalho, traz o indicativo de que haveria certo garantismo em relação à questão de valorização laboral. Logo adiante, no capítulo $7^{\circ}$, afirma ainda que, dentre os direitos sociais, estavam não só o salário mínimo, mas o "piso salarial proporcional à extensão e a complexidade do trabalho" (BRASIL, 1988, p. 08), assim como nos demais elementos contidos no tópico próprio que aborda a educação, a cultura e o desporto.

Nesse sentido, a média salarial razoável precisa ter como parâmetro um referencial mínimo que, mesmo considerando as distorções financeiras de caráter geográficas, seja satisfatório para que o profissional tenha condições de sobreviver com dignidade, custeando suas necessidades familiares, sociais e intelectuais. Para tanto, duas referências se tornam importantes: o salário mínimo nacional e o salário mínimo idealizado pelo Departamento Intersindical de Estatísticas e Estudos Socioeconômicos (DIEESE).

O Quadro 4, abaixo, traça um paralelo indicando a evolução do Produto Interno Bruto (PIB), do salário mínimo no Brasil, o salário mínimo proposto pelo DIEESE com o Piso Salarial Nacional docente nos últimos anos. Expõe-se também o Índice Nacional de Preços ao Consumidor Amplo (IPCA) ${ }^{6}$, que reflete os indicativos de inflação no período abordado, para ter-se uma ideia de expansão ou retração em termos valorativos.

6 O Índice IPCA é oficialmente utilizado pelo governo federal para verificar se os preços praticados no Brasil estão de acordo com as metas de inflação estabelecidas pelo Banco Central do Brasil. A inflação é um processo de elevação de preços que ocorre sempre que há procura maior do que a capacidade de uma economia produzir determinado bem ou serviço. Em resumo, a inflação pode ser de oferta - quando há escassez de produto - ou de demanda - quando a procura é maior do que a quantidade ofertada. O controle da inflação é vital para a manutenção do valor da moeda. Quando o IPCA divulgado pelo IBGE aponta que a inflação real se encontra mais elevada do que a meta estipulada pelo governo, o Banco Central começa a lançar mão de seus instrumentos de controle da elevação dos preços, dando início a um ciclo de alta da taxa básica de juros. Fonte: https://br.advfn.com/indicadores/ipca. Acesso em: 01 mar. 2019. 
Políticas de Financiamento da Educação no Brasil

Quadro 4 - Evolução salarial docente, PIB e Inflação no Brasil

\begin{tabular}{|l|l|l|l|l|l|}
\hline & $\begin{array}{l}\text { Produto } \\
\text { Interno Bruto } \\
\mathbf{( R \$ )}\end{array}$ & $\begin{array}{l}\text { Inflação no } \\
\text { Período (\%) }\end{array}$ & $\begin{array}{l}\text { Piso Salarial } \\
\text { Profissional } \\
\text { Nacional (R\$) }\end{array}$ & $\begin{array}{l}\text { Salário } \\
\text { Mínimo (R\$) }\end{array}$ & $\begin{array}{l}\text { Salário Mínimo } \\
\text { Necessário/DIEESE (R\$) }\end{array}$ \\
\hline $\mathbf{2 0 0 8}$ & 2,9 trilhões & 5,9 & ---------- & 415,00 & $2.001,50$ \\
\hline $\mathbf{2 0 0 9}$ & 3,1 trilhões & 4,3 & 950,00 & 465,00 & $2.042,43$ \\
\hline $\mathbf{2 0 1 0}$ & 3,6 trilhões & 5,9 & $1.024,67$ & 510,00 & $2.110,25$ \\
\hline $\mathbf{2 0 1 1}$ & 4,1 trilhões & 6,5 & $1.187,14$ & 545,00 & $2.272,44$ \\
\hline $\mathbf{2 0 1 2}$ & 4,4 trilhões & 5,8 & $1.451,00$ & 622,00 & $2.505,47$ \\
\hline $\mathbf{2 0 1 3}$ & 4,8 trilhões & 5,9 & $1.567,00$ & 678,00 & $2.765,33$ \\
\hline $\mathbf{2 0 1 4}$ & 5,5 trilhões & 6,4 & $1.697,39$ & 724,00 & $2.925,15$ \\
\hline $\mathbf{2 0 1 5}$ & 5,9 trilhões & 10,6 & $1.917,64$ & 788,00 & $3.280,75$ \\
\hline $\mathbf{2 0 1 6}$ & 6,2 trilhões & 6,3 & $2.135,64$ & 880,00 & $3.875,13$ \\
\hline $\mathbf{2 0 1 7}$ & 6,6 trilhões & 2,9 & $2.298,80$ & 954,00 & 3.744 .51 \\
\hline $\mathbf{2 0 1 8}$ & 6,8 trilhões & 3,7 & $2.455,35$ & 998,00 & 3.755 .25 \\
\hline
\end{tabular}

Fonte: Elaboração do autor com base em IBGE/DIEESE/MEC.

Observa-se que, nesse período, o piso salarial docente subiu $158,45 \%$, enquanto o salário mínimo subiu 140,48\%. Subtraindo a inflação acumulada entre 2009 e 2018, que correspondeu a $58,3 \%$, observa-se que os docentes tiveram um ganho real de $100,15 \%$, ou seja, em uma década o salário praticamente dobrou com a política do piso salarial nacional.

O salário mínimo teve no período citado um ganho real de $82,18 \%$, bem abaixo do valor percebido pelos professores. Fato é que nesse contexto há uma distribuição de recursos para a educação bem superior às de anos anteriores e isso fica expresso não só pelos índices de reajustes do piso salarial, mas também pela destinação de maior tempo livre remunerado aos docentes para planejamento de seus afazeres.

Se comparado o salário mínimo necessário estipulado pelo DIEESE com o piso salarial profissional docente, percebe-se que este saltou de $46,5 \%$ de 2009 para $65,3 \%$ em 2018 . Em outras palavras, houve uma aproximação positiva de quase $20 \%$, o que denota uma valorização em termos materiais da profissão docente. No período analisado, o PIB evoluiu $134,48 \%$. Isso expressa que os recursos destinados à expansão salarial superaram a proporção de crescimento das riquezas do País.

\section{Considerações finais}

Para que o Brasil atinja patamares de países desenvolvidos no quesito qualidade da educação, o ideal seria aplicar ao menos $10 \%$ do PIB em manutenção e desenvolvimento de ensino. Em sua evolução histórica recente, o índice nunca se distanciou de 5\%. A ideia de utilização na educação dos ganhos com royalties pela exploração do petróleo despontou como um projeto exequível nesse sentido. A lei $n^{0} 12.858$, de 09 de setembro de 2013 deu início a uma dimensão distributiva de recursos provenientes da exploração de petróleo para o suprimento de $75 \%$ para educação e $25 \%$ para saúde. 
Com a ascensão da agenda conservadora e neoliberal tornou-se comum, principalmente por meio das mídias alternativas e redes sociais, a divulgação de que o Brasil investe muito em termos proporcionais ao PIB se comparado a outros países. Na verdade, apesar de o valor numérico de investimento por muitas nações realmente ser inferior, essas informações revelam-se falaciosas quando melhor analisadas segundo a realidade brasileira, porque se desconsidera o investimento por aluno ${ }^{7}$.

A ideia de estipular um parâmetro mínimo por aluno é fruto de reflexão da sociedade civil organizada por intermédio da Campanha Nacional pelo Direito à Educação, ratificada parceria técnica desta com o Conselho Nacional de Educação pelo parecer CNE/CEB $n^{\circ}$ 08/2010, com a finalidade de aprofundar análises estatísticas no intuito de aproximar da execução aquilo que ficou recentemente preceituado como "qualidade social".

Outra questão pertinente e que quase sempre é desconsiderada é o aspecto histórico. Enquanto em um passado recente o Brasil destinava baixíssimos investimentos à manutenção e desenvolvimento do ensino, boa parte do mundo moderno investia exponencialmente mais, traduzindo o momento atual mais como consequência de um longo processo. Aqueles que investiram mais outrora agora colhem os frutos.

Percebe-se que o processo de constituição histórico-organizativa da educação brasileira propiciou o surgimento de uma pluralidade de sistemas. Soma-se a isso os embates travados para se conseguir alocar recursos financeiros mínimos para financiar a educação em suas diversos níveis e etapas.

A qualidade do trabalho docente é, em certa medida, consequência desses paradoxos. Não se pode deixar de considerar que o formato da profissão também possui peculiaridades de gênero e de áreas do saber que explicam tanto sua configuração laboral quanto sua constituição associativa.

De qualquer maneira, pensar a qualificação do trabalho docente e da educação requer esforços da sociedade no sentido de ampliar os investimentos na formação inicial e continuada dos profissionais, melhorar seus salários bem como investir no aprimoramento das estruturas físicas das instituições de ensino.

\section{Referências}

BOITO JR., Armando. Política neoliberal e sindicalismo no Brasil. São Paulo: Xamã, 1999.

BRASIL. Decreto-Lei № 4.958, De 14 De Novembro De 1942. Institue o Fundo Nacional do Ensino Primário e dispõe sobre o Convênio Nacional de Ensino Primário. Diário Oficial da União, Rio de Janeiro, 1942.

BRASIL. Constituição dos Estados Unidos do Brasil (de 18 de Setembro de 1946). A Mesa da Assembleia Constituinte promulga a Constituição dos Estados Unidos do Brasil e o Ato das Disposições Constitucionais Transitórias, nos termos dos seus arts. 218 e 36, respectivamente, e manda a todas as autoridades, às quais couber o conhecimento e a execução desses atos, que os executem e façam executar e observar fiel e inteiramente como neles se contêm. Diário Oficial da União, Rio de Janeiro, 1946.

7 A Campanha Nacional pelo Direito à Educação desenvolve trabalhos técnicos no sentido de elucidar essas questões. Ver mais em: http://www.custoalunoqualidade.org.br/o-que-e-caqi-e-o-caq. 
Políticas de Financiamento da Educacão no Brasil

BRASIL. Lei $n^{\circ}$ 4.024, de 20 de dezembro de 1961. Fixa as Diretrizes e Bases da Educação Nacional. Diário Oficial da União, Brasília, 1961.

BRASIL. Constituição da República Federativa do Brasil, de 24 de janeiro de 1967. Diário Oficial da União, Brasília, 1967.

BRASIL. Emenda Constitucional $n^{\circ}$ 01, de 17 de outubro de 1969. Edita o novo texto da Constituição Federal de 24 de janeiro de 1967. Diário Oficial da União, Brasília, 1969.

BRASIL. Lei $n^{\circ}$ 5.692, de 11 de agosto de 1971. Fixa Diretrizes e Bases para o ensino de $1^{\circ}$ e $2^{\circ}$ graus, e dá outras providencias. Diário Oficial da União, Brasília, 1971.

BRASIL. Emenda Constitucional $\mathrm{n}^{\circ} 24$, de 01 de dezembro de 1983. Estabelece a obrigatoriedade de aplicação anual, pela União, de nunca menos de treze por cento, e pelos Estados, Distrito Federal e Municípios, de, no mínimo, vinte e cinco por cento da renda resultante dos impostos, na manutenção e desenvolvimento do ensino. Diário Oficial da União, Brasília, 1983.

BRASIL. Constituição da República Federativa do Brasil, de 05 de outubro de 1988. Diário Oficial da União, Brasília, 1988.

BRASIL. Lei $n^{\circ}$ 9.394, de 20 de dezembro de 1996. Estabelece as diretrizes e bases da educação nacional. Diário Oficial da União, Brasília, 1996.

BRASIL. Lei $n^{\circ} 11.494$, de 20 de junho de 2007. Regulamenta o Fundo de Manutenção e Desenvolvimento da Educação Básica e de Valorização dos Profissionais da Educação FUNDEB, de que trata o art. 60 do Ato das Disposições Constitucionais Transitórias; altera a Lei 10.195, de 14 de fevereiro de 2001; revoga dispositivos das Leis $n^{\circ} 9.424$, de 24 de dezembro de 1996, 10.880, de 9 de junho de 2004, e 10.845, de 5 de março de 2004; e dá outras providências. Diário Oficial da União, Brasília, 2007.

BRASIL. Lei n 11.738, de 16 de julho de 2008. Regulamenta a alínea "e" do inciso III do caput do art. 60 do Ato das Disposições Constitucionais Transitórias, para instituir o piso salarial profissional nacional para os profissionais do magistério público da educação básica. Diário Oficial da União, Brasília, 2008.

BRASIL. Parecer CNE/CEB No: 08/2010. Estabelece normas para aplicação do inciso IX do artigo $4^{\circ}$ da Lei $n^{\circ} 9.394 / 96$ (LDB), que trata dos padrões mínimos de qualidade de ensino para a Educação Básica pública. Brasília, 2010.

BRASIL. Lei N 12.858, de 9 de Setembro de 2013. Dispõe sobre a destinação para as áreas de educação e saúde de parcela da participação no resultado ou da compensação financeira pela exploração de petróleo e gás natural, com a finalidade de cumprimento da meta prevista no inciso VI do caput do art. 214 e no art. 196 da Constituição Federal; altera a Lei n 7.990, de 28 de dezembro de 1989; e dá outras providências. Diário Oficial da União, Brasília, 2013.

BRASIL. Lei no 13.005, de 25 de junho de 2014. Aprova o Plano Nacional de Educação e dá outras providências. Diário Oficial da União, Brasília, 2014.

MATO GROSSO DO SUL. Lei n 4.621 , de 22 de dezembro de 2014. Aprova o Plano Estadual de Educação de Mato Grosso do Sul, e dá outras providências. Diário Oficial, Campo Grande, 2014. 
Políticas de Financiamento da Educacão no Brasil

OLIVEIRA, Regina Tereza Cestari de. A LDB e o contexto nacional: o papel dos partidos políticos na elaboração dos projetos - 1988 a 1996. 1997. Tese (Doutorado em Educação) Universidade Estadual de Campinas, Campinas, 1997.

VICENTINI, Paula Perin; LUGLI, Rosário Genta. História da profissão docente no Brasil: representações em disputa. São Paulo: Cortez, 2009.

Daniel Stockmann é doutorando em Educação pela Universidade Federal de Mato Grosso do Sul (UFMS), Mestre em Sociologia pela Universidade Federal da Grande Dourados (UFGD), Especialista em Supervisão, Orientação e Inspeção Escolar pela Sociedade Educacional de Santa Catarina (SOCIESC). Graduado em Filosofia pela Universidade Católica Dom Bosco (UCDB) e em Pedagogia pela Faculdade Paulista São José. Supervisor de Gestão Escolar (SED/MS). Possui experiência em Gestão da Educação, História, Políticas Públicas, Movimentos Sociais e Ação Coletiva.

ORCID: http://orcid.org/0000-0002-0623-8779

E-mail: danielstk@hotmail.com 


\section{Editores do volume 11}

Márcia Aparecida Jacomini - Universidade Federal de São Paulo, Brasil

José Marcelino de Rezende Pinto - Universidade de São Paulo, Brasil

\section{Comitê Editorial}

Nalú Farenzena - Universidade Federal do Rio Grande do Sul, Brasil

Juca Gil - Universidade Federal do Rio Grande do Sul, Brasil

Theresa Adrião - Universidade Estadual de Campinas, Brasil

Ângelo Ricardo de Souza - Universidade Federal do Paraná, Brasil

\section{Conselho Editorial}

\section{Alejandro Morduchowicz}

Universidad Pedagógica, Provincia de Buenos Aires, Argentina

Andréa Barbosa Gouveia

Universidade Federal do Paraná, Brasil

Fernanda Saforcada

Universidade de Buenos Aires, Argentina

Jacques Velloso

Universidade de Brasília, Brasil

João Monlevade

Senado Federal, Brasil

Jorge Abrahão de Castro

Instituto de Pesquisa Econômica Aplicada / IPEA, Brasil

Lisete Regina Gomes Arelaro

Universidade de São Paulo, Brasil

Luis Carlos Sales

Universidade Federal do Piauí, Brasil

Luiz de Sousa Junior

Universidade Federal da Paraíba, Brasil

Luiz Fernandes Dourado

Universidade Federal de Goiás, Brasil

Magna França

Universidade Federal do Rio Grande do Norte, Brasil

Marcos Edgar Bassi

Universidade Federal de Santa Catarina, Brasil

Maria Angélica Pedra Minhoto

Universidade Federal de São Paulo, Brasil

Maria Beatriz Luce

Universidade Federal do Rio Grande do Sul, Brasil

Maria Dilnéia Espíndola Fernandes

Universidade Federal de Mato Grosso do Sul, Brasil

Nelson Cardoso do Amaral

Universidade Federal de Goiás, Brasil

Nicholas Davies

Universidade Federal Fluminense, Brasil

Robert E. Verhine

Universidade Federal da Bahia, Brasil

Romualdo Portela de Oliveira

Universidade de São Paulo, Brasil

Rosana Gemaque Rolim

Universidade Federal do Pará, Brasil

Rubens Barbosa de Camargo

Universidade de São Paulo, Brasil

Theresa Adrião

Universidade Estadual de Campinas, Brasil

Tristan McCowan

University of London, Reino Unido

Vera Jacob

Universidade Federal do Pará, Brasil

Vera Peroni

Universidade Federal do Rio Grande do Sul, Brasil

Vitor Henrique Paro

Universidade de São Paulo, Brasil

\section{Equipe editorial}

Apoio ao Comitê Editorial: Caio Cabral da Silva

Diagramação, Revisão de português e normalização: Edson Leonel de Oliveira

Revisão de inglês: Sabrina Ferreira

Fineduca - Revista de Financiamento da Educação

Associação Nacional de Pesquisa em

Financiamento da Educação

e-mail: revista.fineduca@gmail.com | site: http://seer.ufrgs.br/fineduca 